\title{
Recrystallization Microstructure Character of Annealing Strip Steel Based on the Compact Strip Production*
}

\author{
Huiping REN**, Degang LI***, Haiyan WANG** and Zili JIN** \\ ** School of Material and Metallurgy, Inner Mongolia University of Science and \\ Technology, Baotou 014010, Inner Mongolia, China \\ E-mail:renhuiping@sina.com \\ *** Baotou Steel Group Corporation, Baotou 014010, Inner Mongolia, China
}

\begin{abstract}
Recrystallization microstructure evolution in cold rolled low carbon compact strip production (CSP) steel was observed by means of optical microscope and transmission electron microscope (TEM).The influence of fine precipitates on microstructure of strip steel during the recrystallization annealing was analysed by using Small Angle X-ray Scattering (SAXS) technique, and the textures evolution was investigated by means of ODF analysis. It was found that the deoxidation residual solute precipitate at the grain boundary during rapid cooling in the CSP process, these fine particles responsible for retarding ferrite grain coalescence and growth during annealing, thus the recrystallization microstructure of CSP strip steel show unique characteristics.
\end{abstract}

Key words: Recrystallization, Microstructure, Csp, Steel

\section{Introduction}

It has been proved that the Compact strip production(CSP) is an advanced manufacturing technology, which produces hot strip using a short production line owing to science, technology and engineering ${ }^{[1,2]}$. The conditions of compact strip production influence the texture and microstructure of ferrite and thus modify the mechanical behaviour of the final products ${ }^{[3]}$. Due to the difference in casting and rolling process, the type, size, and distribution of precipitates in CSP steels were different from that of conventional steel. However, not much information is available about the effect of these inclusions on grain structure of the steels during thermomechanical processing. Therefore, researchers pay great attention to the microstructure evolution, texture formation, distribution of precipitates and their influence on mechanical properties ${ }^{[4,5]}$. The principal aim of this study was to investigate the effect of oxide dispersion and microalloy precipitates on the recrystallization and ferrite transformation in low carbon steel, thus to the characteristics of recrystallization microstructure.

\section{Experimental Method}

The steels for this study were industrially prepared and their chemical compositions

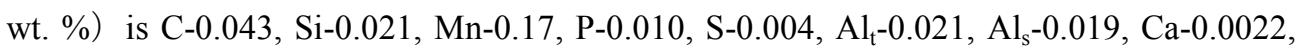
$\mathrm{O}-0.0036, \mathrm{~N}-0.0053$. The hot rolled sheet was cold rolled to a thickness of $1.0 \mathrm{~mm}$ under lubrication, and then followed annealing at $680^{\circ} \mathrm{C}$ for 5 to 120 seconds to recrystallize.

The microstructures of the low carbon steel were studied using an optical microscope. For the characterization of nano-sized precipitates, a transmission electron microscope (TEM) of JEM JEOL 2010 was used. Precipitates were obtained after removing ferric oxide

${ }^{\star}$ Received 16 Nov., 2009 (No. e159) [DOI: 10.1299/jmmp.4.1111]

Copyright $\odot 2010$ by JSME 
layer of CSP specimen low temperature electrolysis, and then separated using chemistry dissolving method. Size distributions of particles were measured by means of small angle X-ray scattering (SAXS) goniometer according to GB/T13221-91 (ISO/TS 13762-2001).The recrystallization textures evolution of the steel were investigated by ODF analysis. The hardness of the annealed specimens was measured using the Vickers hardness method.

\section{Results and Discussion}

The mechanical performance evolvement during annealing at $680^{\circ} \mathrm{C}$ is presented in Fig.1 in terms of the hardness change. The steel shows evident softening in the initial aging stages, which can be inferred from the decrease in hardness. However, after 60 seconds, the hardness has decreased to a substantial amount (approximately 180HV). As seen in this Figure, the hardness value changes very little with the aging time increasing.

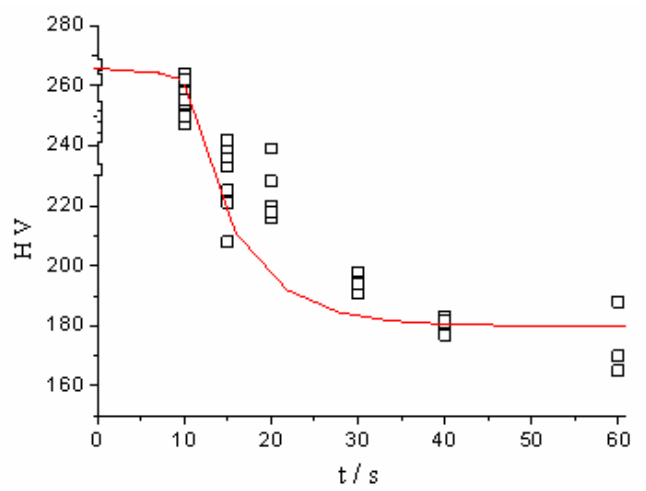

Fig.1 Age hardness curve of experiment steel, aging at $680^{\circ} \mathrm{C}$

Fig.2 shows the microstructure of the experiment steel after $70 \%$ cold rolled and annealed at $680^{\circ} \mathrm{C}$ for $5 \mathrm{~s}$ to $60 \mathrm{~s}$. After annealed for 5 seconds, the microstructure still keeps cold rolled character (Fig.2 (a)). With the time increasing, Fig.2 (b) reveals the well recrystallized ferritic microstructure, which is characterised by equi-axis grain about 3.5 to $4.5 \mu \mathrm{m}$ in diameter. It is obvious that, after full recrystallization, there was no evident change of grain size with the annealing time increasing (Fig.2(c)).
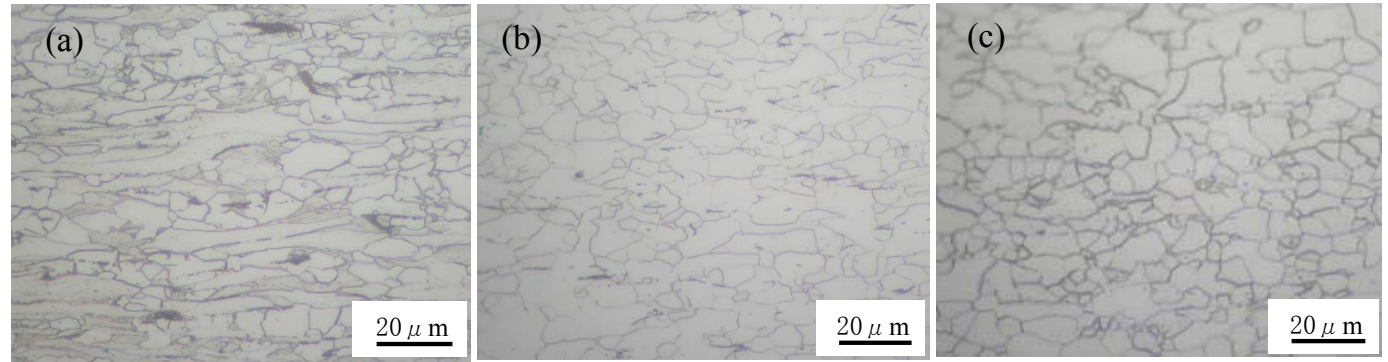

Fig.2 Optical micrographs of the steel after cold rolled and annealed at $680^{\circ} \mathrm{C}$ for (a) $5 \mathrm{~s}$ (b) $15 \mathrm{~s}(\mathrm{c}) 60 \mathrm{~s}$

The scale of the ultra-fine ferrite observed after long time annealing suggests the grain coalescence and growth of the intragranular ferrite was restricted. As mentioned above, we could estimate the microstructure evolvement of CSP process ${ }^{[6]}$. It is more likely that the residues of Al-deoxidation and $\mathrm{Mn}$ deoxidation which formed during rapid cooling based on CSP process that led to a significant decrease in growth rate. Thus, the opportunity for coalescence and growth would be limited.

TEM observation was used to investigate the presence of precipitates, Fig. 3 show some small nano-sized precipitates dispersed randomly in ferrite matrix; the average size of particles is 10 to $40 \mathrm{~nm}$. The precipitates may influence the interfacial energy between the 
particle and the matrix as well as the nucleation process of the particles. It would show a very effective pinning in ferrite matrix ${ }^{[7,8]}$. In addition, a few dislocation density was revealed, the dislocation/precipitation interaction in ferrite matrix should highly likely be one of the dominant reasons for strengthening ${ }^{[9]}$.

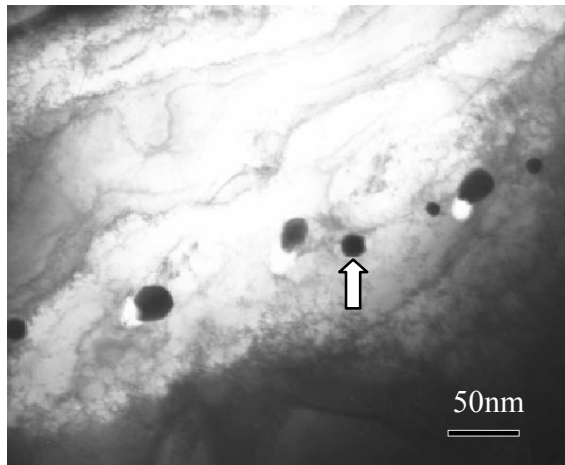

Fig.3 TEM morphology of tiny precipitates

Chemistry dissolving methods were adopted to give further information of the type and mass percentages of precipitates in strip steel. Table 1 shows the result of chemical analysis on the residues of electrolytic extraction, it indicates the mass fraction of $\mathrm{Al}_{2} \mathrm{O}_{3}$ was far higher than other oxide in the steel during the recrystallization annealing process, and nitride, sulfide precipitates were also revealed as the main phase. That means the values generally depend on the contents of the surface-active elements oxygen and sulfur in the iron melt. Therefore, typical morphologies of oxide, nitride and MnS particles should exist in the cases of Al-deoxidation and Mn deoxidation, which has been proved in previous work $^{[10,11]}$. The presence of oxide and other inclusion particles in steels would provide nucleation site for ferrite crystal, and induce crystal fining.

Table 1 Mass percentage of Oxide, Sulfide, and Nitride (wt/\%)

\begin{tabular}{llllllllll}
\hline $\mathrm{Al}_{2} \mathrm{O}_{3}$ & $\mathrm{Cr}_{2} \mathrm{O}_{3}$ & $\mathrm{MnO}$ & $\mathrm{FeO}$ & $\mathrm{NiO}$ & $\mathrm{CaO}$ & $\mathrm{MgO}$ & $\mathrm{SiO}_{2}$ & Sulfide & $\mathrm{AlN}$ \\
\hline 0.00103 & $<0.00001$ & 0.00001 & 0.00001 & $<0.00001$ & 0.00008 & 0.00014 & 0.00016 & 0.018 & 0.019
\end{tabular}

The carbide particles in the steels exist as fine cementite network, and generally located along ferrite grain boundaries or at triple junctions ${ }^{[12]}$. Table 2 shows size distribution of $\mathrm{M}_{3} \mathrm{C}$ particle by means of SAXS, the particles of $10 \sim 18 \mathrm{~nm}$ in diameter account for 0.5 percent at every $1 \mathrm{~nm}^{\prime}$ interval, according to the precipitation strenghtening theory, the fine $\mathrm{M}_{3} \mathrm{C}$ particle would provide great precipitate strengthening. However, grain refinement has been shown just as effective in ultra-low carbon steel, although little evidence of carbide particle formation was observed ${ }^{[13]}$. Take this into account, we conclude that the carbide particles may not the primary reason for grain growth inhibition, while the deoxidizer played a key role in the CSP steels. 
Table 2 Size distribution of $\mathrm{M}_{3} \mathrm{C}$ particle in test steel

\begin{tabular}{cccc}
\hline Size interval(nm) & $\mathrm{f}(\mathrm{D})(\% / \mathrm{nm})$ & Mass Fraction $\%$ & Cumulative $\%$ \\
\hline $5 \sim 10$ & 0.20 & 1.0 & 1.0 \\
$10 \sim 18$ & 0.50 & 4.0 & 5.0 \\
$18 \sim 36$ & 0.35 & 6.3 & 11.3 \\
$36 \sim 60$ & 0.12 & 2.8 & 14.1 \\
$60 \sim 96$ & 0.25 & 9.1 & 23.2 \\
$96 \sim 140$ & 0.25 & 10.9 & 34.2 \\
$140 \sim 200$ & 0.28 & 16.7 & 50.9 \\
$200 \sim 300$ & 0.23 & 22.8 & 73.6 \\
$300 \sim 430$ & 0.09 & 11.8 & 85.4 \\
$430 \sim 620$ & 0.08 & 14.6 & 100.0 \\
\hline
\end{tabular}

As mentioned above, TEM observation and SAXS analysis reveal the clear evidence of the fine precipitates, $\mathrm{M}_{3} \mathrm{C}$ is the most common precipitate in the steels, and $\mathrm{Al}_{2} \mathrm{O}_{3}$ is another important precipitate as well. The presence of $\mathrm{M}_{3} \mathrm{C}$, oxide, sulfide, nitride and other particles in CSP steels provide a reasonable fit for strengthening or grain refining, during following recrystallization annealing and ferrite transformation. Because the pinning force exerted by the precipitates is only a few percent of the stored energy, it would not effectively influence the early stage of recrystallization. For the CSP process with high heating rate, only parts of the stored energy will dissipate during recovery ${ }^{[14]}$. Moreover, in the ferrite region, the precipitation of the fine particles was unequilibrium, therefore the residual solutes will precipitate during the recrystallization annealing. The dynamic interaction of precipitates with the recovery of dislocations seems to be one of the important factors for retardation the recrystallization of the cold rolled strip steel.

The results of XRD texture measurements were used to calculate the orientation distribution function (ODF). Fig. 4 display the ODF in the $\varphi 2=45^{\circ}$ section of Euler space measured in the middle thickness of strip after cold rolled $70 \%$ combining with annealing at $680^{\circ} \mathrm{C}$. As seen in this Figure, the texture data of these two process reveals the steel annealed for 15 s (Fig.4(a)) possesses similar $\{111\}$ intensity with that annealed for 60 s (see Fig.4(b)), except for the texture intensity in the Fig.4(b) show little stronger.
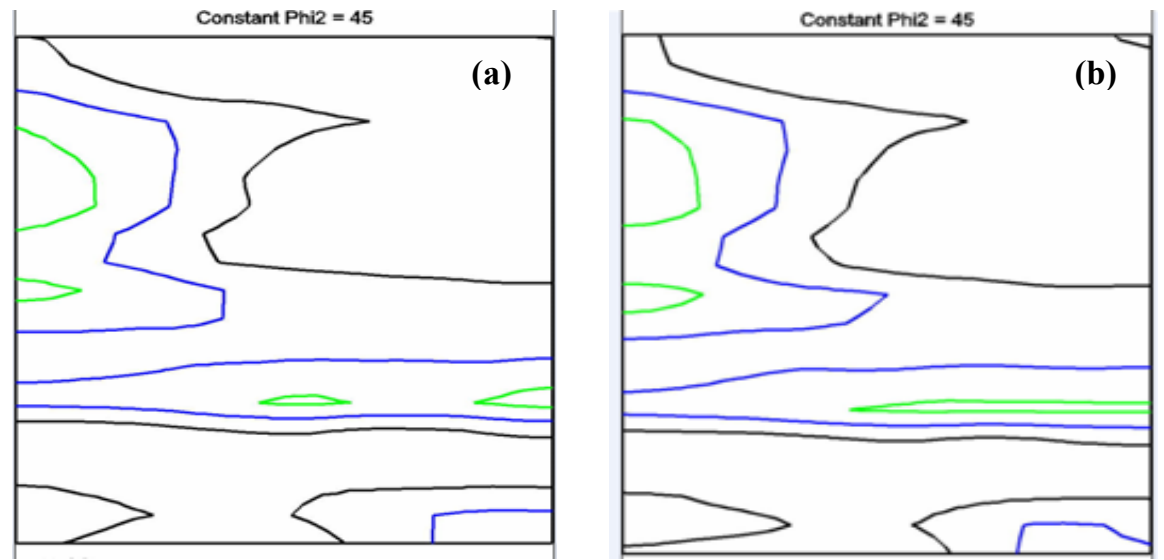

Fig.4 ODF plots (a) $\varphi 2=45^{\circ}$ section of sample, annealed for $15 \mathrm{~s}$; (b) $\varphi 2=45^{\circ}$ section of sample, annealed for $60 \mathrm{~s}$ at strip surface

To sum up, for the cold rolled CSP strip steel, the microstructure and texture have no significant change with the annealing time increasing, the precipitates is the important factors, which have effective influence on the recrystallization microstructure. Compared with the conventional process, the recrystallization processes show their distinct character due to the presence of pinning force exerted by precipitates.

Quality level (cold formability properties) of the ferritic strip steel is determined by 
several factors, such as the chemical composition, the microstructure, the texture, the percentage of cold reduction, the recrystallization annealing process ${ }^{[15]}$. For an example, the $\mathrm{n}$ value is primarily influenced by the chemical composition and the presence of second-phase particles ${ }^{[16]}$. Therefore, the understanding of how inclusions influence grain size in steel will be beneficial to optimize the parameters during thermo mechanical processing of the CSP steel.

\section{Conclusions}

Recrystallization microstructure character of cold rolled low carbon steels produced by compact strip production process were observed in this work, and how grain structures affected by $\mathrm{Al}$ and $\mathrm{Mn}$ deoxidation residues was investigated as well. Fine particles will precipitate during the recrystallization annealing, since deoxidation residual solutes was unequilibrium owing to rapid cooling during CSP process. The particles seem primarily responsible for retarding ferrite grain coalescence and growth during recrystallization annealing, and thus influence the formability properties of the CSP strip steel.

\section{Acknowledgement}

The authors would like to thank National Natural Science Foundation of China (Grant No.50761005) for providing the financial support to enable this research to be carried out.

\section{References}

1. Kang, Y.L, Yu, H., Fu, J., et al. Mater Sci. Eng., vol.A351, 265, 2003.

2. Reip, C.P., Shanmugam, S., Misra, R.D. K., Mater Sci. Eng., vol.A424, 307, 2006.

3. Gardiola, B., Humbert, M., Esling, C., Flemming, G., Hensger, K.E., Mater Sci. Eng., vol.A303,60, 2001.

4. Humbert, M., Gardiola, B., Esling, C., Flemming, G., Hensger, K.E., Acta Materialia, vol.50,1741, 2002.

5. LI, Y., Crowther, D. N., Mitchell, P. S., Baker, T. N., ISIJ Int., vol.42 ,636, 2002.

6. Weng, Y.Q., Ultra-Steel 2000, Tsukuba, Japan, 11, 2000.

7. Liu, Z.zhu., Kobayashi, Y., NAGAI, K., ISIJ Int., vol.44,1560,2004.

8. Nes, E., Ryum, N., Hunderi, O., Acta Metall., vol.33 ,11,1985.

9. Perez, M. and Deschamps, A., Mater Sci Eng., vol.A360, 214, 2003.

10. Wang, H.Y., Ren, H.P., Jin, Z.L., ISIJ Int., vol.48,1451, 2008.

11. Zhang,Q.Y., Wang, L.T., Wang, X.H., ISIJ Int., vol.46, 1421, 2006.

12. Wang, H.Y., Tian, R.B., Ren, H.P., Jin, Z.L., Li, D.G., International Journal of Modern Physics B, Vol. 23, 1080, 2009.

13. Hurley,P. J., Hodgson, P. D., Mater Sci. Eng., vol.A302, 206, 2001.

14. Choi, J.Y., Seong, B. S., Baik, S. C., Lee, H.C., ISIJ Int., vol.42,889, 2002.

15. Asensio, J., Romano, G., Martinez, V. J., Verdeja, J. I., Pero-Sanz, J. A., Materials Characterization, vol.47,119, 2001.

16. Harun, A., Holm, E.A., Clode, M.P., Miodownik, Mark. A., Acta Materialia, vol.54, 3261, 2006. 